\title{
Chapter 3: Cumulative effects assessment requirements in selected developed and developing countries
}

Ayodele Olagunju, Divine Appiah, Paulina Maria Porto Silva Cavalcanti, Bridget Durning, Juan Carlos Tejeda González, Jason MacLean, Richard Morgan, and Rebecca Nelson

\begin{abstract}
Research in cumulative effects assessment (CEA) is advancing in many ways; however, gaps between normative expectations and regulatory approaches remain in many jurisdictions. This chapter profiles CEA requirements and practice in eight countries Australia, Brazil, Canada, Ghana, Mexico, New Zealand, Nigeria and the United Kingdom - and discusses implications for practice effectiveness internationally. Overall, national governments are largely responsible for setting legal frameworks; however, each country differs in terms of requirements, scope, approach and capacity. Experience in developed countries is more advanced when it comes to sector-based innovations, industry-led guidance, and peer review and evaluation. Though capacity is reportedly limited, there has been a shift toward explicit legal provisions for higher-order environmental assessments such as strategic environmental assessment and regional environmental assessment for better CEA outcomes in some developing countries. A systems perspective to CEA legislation, consistent interpretation of provisions by courts and strong political leadership are required to facilitate better practice.
\end{abstract}

Keywords: cumulative effects assessment, case studies; legal framework; best practice; developed countries; developing countries

\section{Background}

Over the past five decades, important legal and policy changes have taken place in many countries following the enactment of the United States' National Environmental Policy Act, 1969, which made environmental impact assessment (EIA) mandatory for federal development projects and initiatives. Various conceptualizations of the appropriate context, 
scope and scale to assess the impacts of human interventions in the environment have emerged, many of which include emphasis on a systems approach and assessment of cumulative environmental effects. This progress has resulted in the advancement of methods, tools, techniques and processes to support cumulative effects assessment (CEA) as well as an increase in the number of countries making regulatory reforms to EIA laws to include CEA requirements. Decades of CEA research have also provided the scientific and technical knowledge base to assess cumulative effects at different scales - project, regional and transboundary (Quinn et al., 2004; Harriman \& Noble, 2007), while being shaped by the growing influence of case law and the needs and concerns of civil society.

While these research advances have increased awareness of the importance of and key processes in CEA, policy and regulatory contexts remain comparatively underexplored. In particular, there is still a need to understand inherent challenges involved in nudging international CEA practice toward best practice and a more holistic focus, beyond individual projects. The broader issues related to defining, implementing and managing cumulative effects, including the appropriate legal, policy, conceptual and technical approaches to support this work, continue to be at the centre of debate about CEA best practices. While many agree that CEA should be part of a rigorous EIA process, how that should proceed, who should be responsible, and what is meant by the term 'cumulative', are questions with mixed responses in various jurisdictions.

To obtain a relatively global picture of progress in CEA practice, we profile a mix of countries from developed (Australia, Canada, New Zealand and the United Kingdom) and developing (Brazil, Ghana, Mexico and Nigeria) nations that, according to our experience and knowledge, have specific legal requirements for CEA or some evidence of progress in practice. To ensure consistency, for each country we address the following questions: 1) what specific legal provisions for CEA exist in the country's EIA law?; 2) are any guidance documents or guidelines issued by the relevant government department to support CEA practice?; 3) what are the current gaps in practice specific to the country?; and 4) what are the strengths in current practice and what implications can be drawn for practice effectiveness locally and internationally? 
Progress and results vary according to country; for example, some countries - even those with advanced EIA systems - have difficulty linking legal requirements to practice because of the absence of robust guidelines and limited capabilities to grapple with the nuances of cumulative effects. However, it is still useful to examine these countries for the insights this provides to practice, legal and policy reforms, and international research on CEA. The chapter highlights progress and experience with CEA for the benefit of researchers, regulators and policy makers within the selected countries and in comparable jurisdictions, but more importantly, identifies foundational issues that are central to strengthening CEA practice internationally.

\section{Case studies from developed countries}

\section{Australia}

Australian EIA legislation occurs at both national and state/territory levels and generally links EIA to authorizations that are required before activities may proceed. The activities that require EIA vary by jurisdiction (Bates, 2016). Much of the legal and policy focus on CEA in Australian EIA relates to extractive resources projects, especially the cumulative effects of mining, petroleum and gas activities on the quantity and quality of water resources. Formal government and parliamentary inquiries have discussed concerns about inadequate consideration of cumulative effects in this context, such as the Australian Senate Environment and Communications References Committee, 2018 (Hunter, 2017).

The EIA legislation of Australian states tends not to expressly mention or define cumulative effects, but to leave requirements for CEA to subordinate legislation (regulations) or non-binding policy documents. Regulations made under New South Wales' Environmental Planning and Assessment Act, 1979 require consideration of 'any cumulative environmental effect with other existing or likely future activities' (Environmental Planning and Assessment Regulation, 2000, cl. 228(1)(o)). CEA policy guidelines for 'State significant projects' under these arrangements were being developed at the time of writing, while existing guidelines for wind farms refer to cumulative impacts, though not in detail (Department of Planning and Environment (NSW), 2016; 2018). 
State-level policy guidance on CEA in EIA tends to mention cumulative effects only briefly (see, for example, ACT Government, 2017; Environmental Protection Authority (Western Australia), 2018), or to provide very limited guidance (Department of Sustainability and Environment (Victoria), 2006); Environment Protection Authority (Tasmania), 2019). Accordingly, some industry sectors have produced their own CEA guidance (for example, see Kaveney et al., 2015) and pursued collaborative approaches to address the cumulative effects of resources extraction (Porter et al., 2013).

Significant public concern about the cumulative effects of rapidly expanding coal seam gas (CSG, also known as coalbed methane) extraction recently led to Australia's first national environmental legislative reference to cumulative effects, albeit one limited to the water resources context. Amendments to the Environment Protection and Biodiversity Conservation Act, 1999 (EPBC Act) (Commonwealth) in 2013 require assessment and approval of any activity involving CSG or a large coal mine that 'has, or is likely to have, a significant impact on water resources ... a) in its own right; or b) when considered with other developments, whether past, present or reasonably foreseeable developments' (s. 528). This requirement is accompanied by federal policy guidance (Department of the Environment (Commonwealth), 2013) and technical guidance on CEA-related information that proponents must provide in their EIA (IESC, 2018).

A strength of this approach is its use of a statutory Independent Expert Scientific Committee (EPBC Act, ss. 505D, 528) to peer review proponent-produced CEA and advise the Minister for the Environment, the decision-maker under the EPBC Act. Queensland's CSG-specific regime for CEA in relation to water resources (Water Act, 2000 (Queensland), ch. 3), which is largely industry-funded, is unusually detailed by Australian standards, though it protects groundwater-dependent ecosystems relatively weakly. Another comparative strength of Queensland's arrangements is the relatively proactive approach to designating 'cumulative management areas' and the clear framework for regularly predicting and reporting impacts in these areas. The comparative clarity of this framework should help support practice effectiveness and transparency, notwithstanding the implementation challenges and gaps outlined below. However, the detail of specific 
arrangements would require considered modification for how they might apply to valued environmental components (VECs) outside the groundwater context.

Special arrangements related to CEA apply in marine settings. The regulation of cumulative impacts on the Great Barrier Reef is being pursued under a strategic assessment under Part 10 of the EPBC Act and accompanying detailed policy guidance (Great Barrier Reef Marine Park Authority, 2014; 2018). The National Offshore Petroleum Safety and Environmental Management Authority (NOPSEMA), which has environmental approval functions under the Offshore Petroleum and Greenhouse Gas Storage Act, 2006 (Commonwealth) and Offshore Petroleum and Greenhouse Gas Storage (Environment) Regulations, 2009 (Commonwealth), considers cumulative effects of a project and issues brief guidance mentioning this (NOPSEMA, 2018).

Australian CEA practice faces important challenges in the contentious context of resources extraction, especially in relation to data availability and sharing (particularly baseline groundwater data), availability of appropriate models, and uncertainty about allocating responsibility for dealing with cumulative impacts among project proponents (Nelson, 2019). CEAs for CSG tend to perform particularly poorly in relation to clearly identifying the temporal scope of assessment and considering the probable effects of climate change. These are crucial issues given the long durations of likely effects (Nelson, 2019). Assessing cumulative effects on Aboriginal cultural heritage, including culturally significant VECs, is a further notable gap in current policy and practice.

\section{Canada}

Cumulative effects are conceptualized in the Canadian research and practice context as adverse effects on VECs caused by the interaction of multiple human activities and natural processes across time and space (typically a region) (Olszynski et al., 2017). Despite the considerable scholarly attention devoted to CEA in Canada and many other countries, CEA understanding remains weak, CEA practices are wanting, and overall progress on promoting CEA is slow (Sinclair et al., 2017).

CEA is listed as one of the purposes of the Canadian Environmental Assessment Act $(C E A A), 2012$ and was previously a requirement of the former $C E A A, 1995$. The purposes 
of CEAA, 2012 are, among others, 'to encourage the study of the cumulative effects of physical activities in a region and the consideration of those study results in environmental assessments' (s. 52). CEA is also an element of the first mandatory factor to be considered under $C E A A, 2012$. Pursuant to subsection 19(1)(a) of $C E A A, 2012$, a project EIA must take into account the environmental effects of the project, including 'any cumulative environmental effects that are likely to result from the designated project in combination with other physical activities that have been or will be carried out' (ss. 19(1)(a)).

CEA is also sometimes carried out in conjunction with other federal regulatory processes, including species at risk management plans under the Species at Risk Act (SARA, ss. 65-70). CEA can also be conducted as part of provincial and territorial EIAs, including complementary regional environmental assessment (REA) and strategic environmental assessment (SEA) processes, and cumulative effects, when assessed, may also be considered as part of the decision-making process under the new Canadian Navigable Waters Act (ss. 7(1)(7)(e) and 29(1)(g)). Notably, however, none of these processes requires CEA.

The Operational Policy Statement (OPS) on Assessing Cumulative Environmental Effects under $C E A A, 2012$ seeks to clarify the requirements under $C E A A, 2012$ relating to CEA (Government of Canada, 2012). The OPS stipulates that all CEAs should include the following five steps: 1) scoping (including the temporal and spatial identification of VECs in relation to other past, present, and future biophysical activities); 2) data analysis and modeling (including the incorporation of local community and Indigenous traditional ecological knowledge); 3) mitigation (assessing the technical and economic feasibility of mitigation measures); 4) significance (predicted in relation to the Canadian Environmental Assessment Agency's significant adverse environmental effects guidelines 1); and 5)

1 Refer to the "significant adverse environmental effect" guidelines issued by the Canadian Environmental Assessment Agency (2016). 
follow-up (including the verification of EA accuracy and the determination of the effectiveness of implemented mitigation measures).

Additional CEA guidance is provided by the Expert Panel for the Review of Environmental Assessment Processes convened by the federal government. In its report Building Common Ground: A New Vision for Impact Assessment in Canada, the Expert Panel defines cumulative effects as changes to the five pillars of sustainability environment, economy, social, cultural, and health - caused by multiple interactions among human activities and natural processes that accumulate across space and time (Government of Canada, 2017). The Expert Panel strongly recommended the use of REAs in cases of cumulative effects on federal lands and marine areas, and emphasized the importance of identifying and evaluating alternative development scenarios as part of CEA.

These recommendations, however, were not carried through in the new federal Impact Assessment Act (IAA) enacted in June 2019. Instead, the $I A A$, like CEAA, 2012 before it, encourages the assessment of cumulative effects on a regional basis (s 6(1)(m)), and includes "any cumulative effects that are likely to result from the designated project" among the many mandatory factors to be considered when conducting an EIA (s 22(1)(a)(ii)), tracking the very same language quoted above that was used in CEAA, 2012. This weak requirement, however, has been consistently honoured more in the breach than in compliance.

Accordingly, CEA practice in Canada remains at best deficient, and at worst entirely absent from EIA processes and economic decision-making; much the same can be said of CEA's conceptually-close cousin, adaptive management (Olszynski, 2017). However, the gap between academic research on the potential of CEA, which is considerable, and the actual practice of CEA, which is negligible, is only partly due to the lack of robust CEA legislation. While more firmly legislating CEA - along with REA and $\mathrm{SEA}_{2}$ - is certainly important, equally important is mainstreaming what Sinclair et al.

\footnotetext{
2 The new $I A A$, which repeals and replaces $C E A A, 2012$, provides for the possibility of regional and strategic assessments at the sole discretion of the Minister of the Environment (whether on the Minister's own initiative or in response to a public request: ss. 92-103). Otherwise, the new legislation provides neither a mechanism for triggering and mandating regional or strategic assessments nor any criteria for how to conduct such assessments. The new legislation is likewise silent with respect to the outcome of regional and strategic assessments; while an assessment report is to be filed with the Minister and made public, there is no provision
} 
(2017) characterize as the 'CEA mindset.' They argue that rather than dismissing CEA as a thorny distraction from the usual business of project-level EIAs, CEA should be at the core of every assessment of VEC conditions affected by human activity. Ideally, CEA should be conducted at the REA and SEA levels, but whatever the given level of assessment project, sectoral, regional, or strategic - it is essential to adopt a holistic approach capable of considering cumulative effects across all levels (Harriman \& Noble, 2008).

Crucially, this means abandoning the predominant major-project approach to EIA in Canada. Designating only "major" projects - while exempting a great many others (Government of Canada, 2015) - for what is a siloed, project-by-project EIA process3 significantly hinders the ability to assess cumulative effects and utilize CEA to facilitate the transition toward greater sustainability.

Canadian CEA scholars recognize that there is a continuum of CEA practice, and that aspects of meaningful CEA do sometimes occur, albeit in a limited number of EIAs (Creasey \& Ross, 2009). Counter-intuitively, the limitations of CEA understanding and practice suggest options for improvement. This counter-intuition is strengthened by the absence of serious debate in Canada over the importance of effective CEA. Perhaps the most important lesson, arising out of both the limitations of Canadian CEA practice and the various proposals for CEA reform, is the need to be far more realistic about the CEA capacity of private-sector project proponents. It is long past time for government agencies to curtail their reliance on private-sector proponents and assume responsibility for ensuring both effective CEA practice and more effective EIA overall (MacLean, 2016; MacLean et al., 2016; MacLean, 2019). While CEA practice is particularly and unjustifiably weak in Canada, growing attention to "Anthropocene risks" - that is, cross-scale systemic environmental risks with global effects - is generating increased interest in CEA-like thinking (Keys et al., 2019). Case studies from China and India focusing on sustainable water management in historical perspective, for example, illustrate how environmental

for decision-making, and no guidance on how the results of regional and strategic assessments are to be utilized - if at all - in future project assessments.

3 For example, in Canada major oil pipeline projects are assessed on a pipeline-by-pipeline basis, precluding a broader assessment of regional, national, and international energy and economic strategies and their trade-offs with VEC conditions and related dimensions of sustainability (Palen et al., 2014). 
governance is by dint of sheer necessity moving toward a more holistic CEA mindset (Liu et al., 2019).

\section{New Zealand}

The main EIA law in New Zealand is the Resource Management Act, 1991 (RMA) which governs the management of natural and physical resources over most of the country, except the land managed by the Department of Conservation, and offshore resource development (both of these have their own EIA requirements, under separate legislation). The whole approach of the $R M A$ is to ensure adverse environmental effects of resource management activities are recognised during decision-making processes, at the policy and plan levels as well as at the project level. The definition of "effect" in the RMA (s. 3) includes cumulative effects: '. . (d) any cumulative effect which arises over time or in combination with other effects ...' (RMA, s. 3(d)). This is taken as the mandate for assessing cumulative effects, and ensures it is integrated into the broader impact assessment processes.

In relation to proposed projects, resource consent applicants must include an "assessment of environmental effects" (AEE) (that is, an EIA) and that should, when appropriate, include an assessment of cumulative effects along with other impact information. The bulk of the applications nationwide are for small, local activities, so the AEEs for these are generally brief, scoping-style assessments, and would not be expected to contain any treatment of cumulative effects. Major projects have full impact reports and some treatment of cumulative effects would be expected if relevant to the proposal. In relation to policies and plans, the functions of regional and territorial authorities are directly related to the need to recognise and manage effects of resource use, including cumulative effects. For example, at the regional level, regional councils are required to: '[prepare] objectives and policies in relation to any actual or potential effects of the use, development, or protection of land which are of regional significance ...' $(R M A$, s. 30(1)(b)). Similarly, at the district level, the main functions of territorial authorities (district and city councils) include: 
(a) the establishment, implementation, and review of objectives, policies, and methods to achieve integrated management of the effects of the use, development, or protection of land and associated natural and physical resources of the district: (b) the control of any actual or potential effects of the use, development, or protection of land ... (RMA, s. 31(1)).

Regional and territorial authorities prepare policies and plans to meet these requirements, and that framework (together with any National Policy Statements and/or National Environmental Standards produced by central government) provides the context for decisions about proposed activities in the resource consent process. In theory, therefore, the assessment of cumulative effects should occur during policy and plan preparation and as part of the AEEs produced by resource consent applicants. The Ministry for the Environment produced a guide to AEE (that is, EIA) production, last updated in 2006 (NZ Ministry for the Environment, 2006). Given the integrated nature of the process, cumulative effects are mentioned but no specific guidance is given on how to carry out such assessments. More recently the New Zealand Environmental Protection Authority produced a guide on EIA preparation under the Exclusive Economic Zone (EEZ) and Continental Shelf (Environmental Effects) Act, 2012 (for major offshore proposals in the EEZ). This briefly described two broad types of cumulative effect (intra-project and inter-project) but again provided no substantive advice on approaches.

Case law strongly influences EIA practice in New Zealand and the case law around the interpretation of the definition of cumulative effect has been confused, so there has been a lack of clear direction for practitioners. An influential decision by the Court of Appeal (Dye vs Auckland Regional Council [2002] 1 NZLR 337 (CA)) applied a narrow definition of cumulative effects (among other things, that cumulative effects did not include effects of other activities, only those of the activity for which resource consent is being sought). Environment Court Judge Jon Jackson, in a recent paper discussing the assessment of effects under the $R M A$, believes Dye 'has caused ongoing problems when it is applied more widely than its facts justify' (Jackson, 2016, p. 26), and an Environment Court decision in 2017 (Wellington Fish and Game Council v Manawatu-Wanganui Regional Council [2017] 
NZEnvC 37) noted that the relevance of Dye, beyond the immediate context of the original case, had been placed in doubt by subsequent legal decisions.

Apart from Judge Jackson's commentary in 2017, a discussion paper on the Quality Planning website in 2009 is still one of the few substantive treatments of cumulative effects under the $R M A$, but also shows the almost total separation of the legal discourse from the impact assessment literature on CEA. Practice overall at the project level is weak: EIAs for large projects are more likely to address cumulative effects but not always; smaller projects will often lack any consideration. When cumulative effects are addressed, in many cases assessors just look at the totality of effects from a project (that is, the integrated view of project impacts). In other cases, assessors are looking at likely effects added to those from existing activities in a locality (space crowding) and sometimes at possible interactions, but that is less frequent.

Many of the more obvious cumulative effects in New Zealand are associated with the expansion of rural land uses such as dairying, marine farming, and horticulture, or with urban growth around major cities. Ideally these should be addressed through CEA provisions as part of an SEA process linked to regional planning. In New Zealand regional policies and plans are required under the $R M A$, but there is no clear mandate for SEA and little evidence of SEA-type assessments being applied at the regional level (Wilson \& Ward, 2011). Cumulative effects are usually noted in regional plans, especially in their objectives, but with the implication that project level decisions will be sufficient to deal with regional level cumulative impacts. Recent moves to introduce spatial plans at the regional level may encourage fresh thinking on CEA practice.

The main strength of the New Zealand system is the way the consideration of cumulative effects is integrated with the rest of the impact assessment process, and the fact that those processes, in theory, apply at the different levels of decision-making from local to national. However, practice has not lived up to the potential of the system, especially in the absence of strong guidance from the Ministry for the Environment. There are signs that things could be changing for the better. The Environment Court decision NZEnvC 37, cited above, noted with apparent acceptance the applicant's use of a definition of cumulative effects from a NOAA publication, itself based on the US Council for Environmental 
Quality (CEQ) definition. Moreover, another recent decision of the Environment Court upheld an appeal from local residents near Christchurch, New Zealand, and refused consent for a new gravel extraction quarry (Yaldhurst v. Christchurch City Council \& Harewood Gravels Limited, 2017). This was mainly on the grounds that the cumulative impacts of the existing quarries plus the proposed quarry would be significant for the local people. These suggest that judicial interpretation of cumulative effects is finally moving closer to the internationally recognised meaning. Although official guidance has not yet improved, a guide to EIA for major offshore projects by a government research institute (Clark et al., 2017) includes a section on cumulative effects that draws on impact assessment literature, which provides a clear signal for how future practice could evolve.

\section{United Kingdom}

The regulatory requirement to address EIA, including cumulative effects at the project level, was introduced into UK law through the implementation of EC Directive 85/337. This included the requirement to describe the 'direct effects and any indirect, secondary, cumulative. . .effects of the project'.

The most recent revision to the EU Directive (2014/52/EU) was transposed into UK law in 2017. The current key 'generic' legislation for developments subject to the Town and Country Planning Act (1990) is the Town and Country Planning (EIA) Regulations, 2017 (as amended). For major projects in England that are subject to the Planning Act, 2008 (National Infrastructure Planning, n.d.) the relevant legislation is the Infrastructure Planning (EIA) Regulations (2017). Other authorization systems also require EIA and are subject to separate legislation (Marine Works (EIA) (Amended) Regulations, 2017, for example). Glasson and Therivel (2019, Table 3.6) list a total of 28 key UK EIA regulations.

The regulations transpose the requirement EU 2014 EIA directive into law in England and the devolved administrations within the UK (Wales, Scotland and Northern Ireland). This has strengthened the requirement to consider cumulative effects which now must be taken into account when deciding whether a development should be subject to EIA (Annex III of Directive 2014/52/EU) as well as being one of the key areas of assessment (Annex IV): 
Annex IV-Information for the environmental impact assessment report:

5. A description of the likely significant effects of the project on the environment resulting from, inter alia:

(e) the cumulation of effects with other existing and/or approved projects, taking into account any existing environmental problems relating to areas of particular environmental importance likely to be affected or the use of natural resources.

The legislation does not define cumulative effects.

The Planning Inspectorate, the government agency responsible for applications submitted for consent through the Planning Act, 2008, has published an advice note on CEA (PINS, 2019) to support those undertaking assessment for nationally significant infrastructure. This guidance drew heavily on research into current practice by Oxford Brookes University (Durning \& Broderick, 2015). There is no other published government guidance specifically to support CEA practice in EIA. Industry-specific guidance has been published (for example, see RUK, 2013; MMO, 2014; Natural England, 2014; BSI, 2015). Broderick, Durning and Sanchez (2018) set out a generic methodology for CEA which is based on a review of guidance and best current UK and international practice.

The current gaps in CEA practice in the UK include a lack of transparency and robustness in the methodology used to assess the effects and a lack of consistency and understanding of definitions and terminology. This is not unique to the UK and has long been cited as an ongoing challenge (for example, see Cooper \& Sheate, 2002; IEMA, 2011; Durning \& Broderick, 2015; Mitchell \& Wright, 2019). There is a general lack of 'process knowledge' among practitioners on how to do effective CEA (Durning \& Broderick, 2019) including issues such as defining significance and uncertainty in what to include in the assessment (Mitchell \& Wright, 2019). Reflecting the current state of economic cycles, one of the suggested potential barriers to practice proposed by Mitchell and Wright (2019) is 'confidentiality and impartiality'. They suggest that in 'challenging' commercial circumstances there may be a lack of willingness for developers to share information that is not in the public domain which limits the effectiveness of the assessment. 
Assessments of practice (Durning \& Broderick, 2015; 2019; MMO, 2013) demonstrate there are some areas of good practice, although it is notable that this good practice occurs when there is robust guidance which is followed, for example, in offshore renewable energy.

The RUK (2013) guidelines suggested cumulative effects could be categorised as either 'additive' or 'synergistic/in-combination' effects and this definition has been also taken up by other guidance (Natural England, 2014; BSI, 2015; Broderick et al., 2018).

An example of good practice identified by Broderick, Durning and Sanchez (2018, p. 667) from the Hornsea One Offshore Wind Farm as due to:

- the baseline assessment sets out what is included and how the 'long list' of plans, projects and activities has been devised;

- explains how spatial and temporal ranges have been identified;

- the methodology for 'screening' projects in or out is clearly set out and the results are presented in a transparent format.

There is also evidence of good practice emerging in major infrastructure projects which are subject to consenting through the Planning Act, 2008, such as the Port of Tilbury 2 cumulative effects assessment (Tilbury2, n.d.) which was subject to external peer review and evaluation using the evaluation framework set out in Durning and Broderick (2015). This is an example of undertaking a qualitative, high level CEA when insufficient information was available to undertake a quantitative assessment. The Examining Authority, in their recommendation report on whether the development be recommended for approval by the Secretary of State, considered this to be a reasonable and proportionate approach (PINS, 2018).

\section{Case studies from developing countries}

Brazil 
In Brazil, federal law 6.938/81, regulated by federal decree 99.274/90, delimited objectives, principles and instruments of the National Environmental Policy (PNMA), instituted the National Environmental System (SISNAMA) and established EIA as one of its instruments. It also created the National Council for the Environment (CONAMA) as a consultative body chaired by the Minister of Environment and composed of Plenary and Technical Chambers and civil society. EIA was regulated in CONAMA Resolution 01/86 and its application has been linked to environmental licensing. From 1988, it became a mandatory constitutional requirement for project proponents to submit an EIA report, according to the text of the Federal Constitution and, later, in the States Constitutions. The requirement recently became entrenched in complementary federal law 140/2011: 'environmental licensing is the administrative procedure for activities or undertakings that use environmental resources, effectively or potentially polluting or capable, in any way, of causing environmental degradation'.

CONAMA Resolution 01/86, in its Article 6, item II, establishes that an environmental impact study must have:

the analysis of the environmental impacts of a project and its alternatives, through identification, prediction of the magnitude and interpretation of the importance of the probable relevant impacts, discriminating: positive and negative impacts (beneficial and adverse), direct and indirect, immediate and medium and long term, temporary and permanent; their degree of reversibility; its cumulative and synergistic properties; and the distribution of social burdens and benefits (CONAMA, 1986).

However, there is no explicit reference to CEA procedures, nor does it provide guidelines for its implementation. Although projects with potential to generate a high level of pollution are subject to an EIA before environmental licenses are issued, many of these projects are often defined by the boundaries of a river basin as an environmental management unit. EIA studies are usually focused on the environmental impact of the project, without the broader analysis of other existing or planned activities impacting the 
region or ecosystem. In other words, there is no effective treatment of cumulative impacts in Brazilian practice.

Some progress has been recorded in the context of SEA, which, despite being an instrument still under development in Brazil, is gradually directing focus to cumulative impacts of large-scale projects. This is more evident in sectoral policies, such as the energy, oil and gas, transport, mining and tourism sectors, and are largely driven by individual private project developers. There has not been any legal framework or technical guidelines to support practice. An exception is the oil sector, where Ministerial Ordinance No. 198/12 of the Ministry of Mining and Energy, together with the Ministry of Environment, instituted the Environmental Assessment of Sedimentary Areas. The Ordinance makes CEA consideration a condition for granting environmental licensing for exploratory oil and gas blocs located in sedimentary basins, and other related undertakings and activities. In this case, SEA (including consideration of cumulative effects) is helping to shape decisions on areas of relevant mining-energy interest in accordance with the provisions of federal decree 6.678/2008, which approved the VII Sectorial Plan for Sea Resources.

Some Brazilian states, such Minas Gerais and Bahia, are using SEA as a legal tool to understand the environmental impacts of state actions in all its aspects, thereby serving as a decision-making instrument that provides information about the possible environmental consequences of government actions (Valera, 2012). The concept of Integrated Environmental Assessment has also been applied to electric power generation programs to establish minimum environmental thresholds for key environmental indicators in river basins. In both SEA and Integrated Environmental Assessment (IEA), the analysis of socio-environmental effects, including the discussion of the cumulative and synergistic effects of co-located undertakings in river basins are being integrated to planning and decision-making.

CEA practice in Brazil has some gross limitations, most of which have been documented by Sanchez (2006) and continue to be evident in current practice. These include outdated licensing process and requirements (no changes since the 1980s); lack of definitions and clear procedures in the legislation; scarce technical and methodological knowledge on cumulative impact assessment; shifting of environmental impact 
responsibility to private entities that have limited access to environmental information and whose focus is economic gains; limiting CEA consideration to project level, where the analysis is limited to an undertaking's area or a project's direct and indirect influence areas; disregard of the river basin in the delimitation of the project's influence area; proliferation of competing standards and regulations leading to a conflict of institutional competences; lack of information exchange and integration between environmental agencies; and the unregulated practice of the SEA or the IEA. These are issues that require urgent intervention for CEA practice in Brazil to align with international best practice.

\section{Ghana}

Environmental impact assessment, according to Ghana's Environmental Protection Agency (EPA, 1996), is a planning and decision making tool applied in Ghana to proposed undertakings (any activity, project, structure, investment, plan program, and so on) whose implementation or development may have a significant biophysical and social impact. The Environmental Protection Agency Act 490 Section 12(1) is further operative in tandem with the Environmental Assessment Regulations, LI 1652 of 1999, which delineates project undertakings for which EIA is mandatory and those for which EIA process is not a strict requirement. Following a systematic EIA process by a project proponent, an environmental permit is issued as an evidence of the proponent's compliance with the Legislative Instrument (LI) 1652 of 1999.

Currently, there is no explicit provision for CEA in Ghanaian environmental laws, including its Environmental Assessment Regulation document which stipulates the process for EIA practice. However, the scope of environmental impact statement (EIS) mandated by the Agency intrinsically implies a CEA consideration. While the EIA law is mute on CEA - both procedurally and methodologically - individual as well as institutional proponents including government ministries, agencies and departments often take the responsibility to include a CEA section that captures the effects of their projects in combination with other projects. The LI 1652 states that an EIS 'shall also address possible direct and indirect impacts of the undertaking on the environment at the pre-construction, construction and operation, decommissioning and post-decommissioning phases' (LI 1652, 
1999, p. 6). The LI 1652 requirements for assessment of 'indirect impacts' is often interpreted by proponents to mean a requirement for CEA. For example, the proposed Abidjan-Lagos highway corridor project, a flagship project of the Economic Community of West African States (ECOWAS), is a large-scale regional infrastructure development that presented opportunities for consideration of CEA on a regional scale and along the corridor in a transboundary, trans-national context.

CEA in Ghana is also implied in the context of SEA, where developers often take responsibility for addressing issues related to cumulative effects. For example, a full section was dedicated to analysis of 'secondary, synergistic and cumulative effects' in the SEA of the Transportation Integration Plan of Ghana (2010) prepared by Mott MacDonald, a Southampton UK-based consulting firm. In particular, cumulative effects were considered in determining the overall risk levels of environmental sustainability criteria of the Plan with issues such as climate change, air quality, water quality, public health, poverty reduction and cross-sectoral coordination flagged as long term, cumulative effects (Government of Ghana, 2010).

The absence of regulatory requirements, and in consequence, good practice guidance, usually means that no rigorous benchmark exists for regulators to evaluate the adequacy of information on cumulative effects provided by proponents. In addition, though discretionary, information on CEA is only found in EIA reports of Schedule 2 (Mandatory List) projects under the EIA Regulation. These projects include large-scale mining, oil and gas exploration, transportation, energy, agricultural and health developments with standardized thresholds; for example, agricultural projects on lands exceeding 40 hectares or affecting more than 20 families or with irrigation components will ideally require that a CEA is carried out. EIA for many of these large-scale projects are often prepared by international consultants or donor agencies who sometimes choose to adopt a good practice approach - which may require doing CEA - to their EIA process.

The implication is that CEA for small-scale projects, which constitutes the bulk of assessments, are completely non-existent. This is because the concept of CEA is widely unknown to local practitioners. Other problems include the limited training and proficiency of CEA among regulators, which limits the ability to make sound judgment relating to 
CEA. Compounding the challenges of the environmental institutions is the general citizen recalcitrance and, to an extent, intransigence toward due process and compliance with environmental regulations. For instance, project proponents tend to relax on the implementation conditions and the prescribed mitigation submitted through their Environmental and Social Management Plans once permits and development licenses are issued. On the other hand, despite provision for follow-up and monitoring in the EIA regulation (EPA Act 490, p. 3), there is no evidence of post-approval communications and interventions by Agency staff once permits have been issued. Thus, CEA process in Ghana lacks the required consistency, cohesion and institutional environment to thrive (Baxter, 2001).

The general awareness of the concept of CEA among a section of the Ghanaian EIA community provides opportunity to shape the debate on the legal and policy imperative of CEA practice. This is a strength in the Ghanaian context as individual practitioners are taking the initiative to consider cumulative effects in the absence of a clear requirement, though at different levels of sophistication in their approach. This discretionary approach suggests the need for a legislative reform that makes CEA an explicit requirement in EIA process, capacity enhancement for regulators and practitioners, and a policy environment that provides guidance for proponents and developers on best practice CEA.

\section{Mexico}

Mexico has specific provisions for CEA in its environmental law and its EIA specific regulation, especially in the General Law for Environmental Protection and Ecological Balance (LGEEPA)4. The LGEEPA, which came into effect from 28 January 1988 (amended on 5 July 2018), in its Chapter IV (Tools for Environmental Policy) Section V (Environmental Impact Assessment), defines the EIA process that certain federal activities and infrastructure are to follow. The specific regulation of this law for EIA (Regulation for Environmental Impact Assessment5), published 30 May 2000 (amended 31 October 2014),

\footnotetext{
4 Known as Ley General del Equilibrio Ecológico y la Protección al Ambiente in Spanish 5 Known as Reglamento de la LGEEPA en materia de Impacto Ambiental in Spanish
} 
defines cumulative environmental impact as 'the effect in the environment as a result of the increment of the impacts for particular actions caused by the interaction with other past or present impacts' (Chapter I General Provisions, Article 3). It is important to note that the Mexican legal framework does not include future projects/undertakings in its definition contrary to guidance issued by the Ministry of Environment and Natural Resources 6 (SEMARNAT) and other international practice guidelines (Canter \& Ross, 2010; European Commission, 2013; Natural England, 2014).

At the federal level Mexico has two types of EIA (particular and regional) where cumulative impacts are encouraged to be identified; however, it is in the regional type where these impacts are more likely to be recognized because regional EIA was visualized as a type of SEA for urban development plans or programs, and for ecological zoning of land by Mexican authorities (SEMARNAT, n.d., p. 4), although in practice this type is mostly used in big projects like dams, wind farms, highways, and so on. Currently there is no guidance issued by responsible government department to support the formal and systematic CEA practice in Mexico at any level (federal, state or municipal) (Perevochtchikova \& André, 2013). As previously mentioned, a general guidance for regional EIA-type in Mexico exists (SEMARNAT, n.d., p. 61). It draws some recommendations for practitioners, whom according to this guidance, should include in the regional EIA report an analysis of:

- The effects of past, present and future activities that have modified the ecosystems of the region.

- The foreseeable changes over the environment that could reasonably be expected from the project proposed, in combination with other human activities in the Regional Environmental System.

- The assessment of the total sum of similar alterations related with the project proposed, independently of their origin.

- The likely interactions between dissimilar sources of an impact.

6 Known as Secretaría de Medio Ambiente y Recursos Naturales in Spanish 
It is evident that in Mexico the current gaps related to CEA practice are more important than its strengths, but this could be viewed as an opportunity for improvement in the following areas:

- Capacity building: there is little to no training for practitioners and authorities in identification and assessment of cumulative impacts. This is evident in the quality of the EIAs submitted by practitioners, in the authorizations granted by authorities, and more critically in the negative effects to the environment manifested after the development of the authorized projects.

- CEA understanding: splitting of big projects into smaller ones with the intent of not including cumulative impacts in EIA reports is a recurrent practice allowed by Mexican environmental authorities. For example, a project that involves the construction of a liquid natural gas terminal in Manzanillo, Colima, may include the terminal, a railroad deviation, and a $300 \mathrm{~km}$ pipeline from Manzanillo to Guadalajara, Jalisco, in a coastal lagoon planned to be a new port. This project, instead of being submitted as a single EIA or being assessed as a SEA with rigorous consideration of cumulative effects, was split into three single projects with their respective regional EIAs and without considering cumulative impacts. The three projects were independently approved by the authority without weighing the collective impacts of the three projects in addition to other activities in the region.

- Good practice guidance: the non-existence of proper guidance for the identification and assessment of cumulative impacts within the different types of EIA.

- SEA use: the lack of formal and systematic use of SEA that must be addressed as SEA remains the most viable tool to address cumulative impacts (Perevochtchikova \& André, 2013; Gonzalez et al., 2014) and CEA 'should be a central feature of these strategic studies' (Canter \& Ross, 2010, p. 262).

Despite the above, not all is negative. The research community is leading the narrative for good practice CEA in Mexico. A deliberate attempt at translating research to policy in order to meet international CEA standards is what is missing. Bridging the researchpractice gaps in CEA can be fostered in an atmosphere of trust and collaboration, and an 
institutional environment that is committed to best practice environmental protection and natural resources sustainability.

\section{Nigeria}

At the beginning of the 1990s, provisions regulating environmental impacts in Nigeria emerged from three different fronts: the Environmental Guidelines and Standards for the Petroleum Industry in Nigeria, 1991 (EGAS); the Urban and Regional Planning Decree 88, 1992; and the Environmental Impact Assessment Decree 86, 1992. Among these, the only law with specific provision for CEA was the EIA Decree 86 of 1992, which was established by a decree of the then federal military government, entered into force on 10 December 1992 and amended as an Act in 2004 (CAP. E12 L.F.N. 2004). This Act mirrors the United States National Environmental Protection Act and has been the only official legal provision that mandates project proponents to consider impacts beyond their projects.

The Act requires, as part of its provisions for an EIA, that a project proponent conduct 'an assessment of the likely or potential environmental impacts on the proposed activity and the alternatives, including the direct or indirect cumulative, short-term and tong-term effects' (s. 4(d)). Information sharing and consultation are also implied in its objectives, particularly to determine if a project is 'likely to have significant environmental effects on boundary or trans-state or on the environment of bordering towns and villages' (s. 1(c)). The purpose of the provision was to ensure any cumulative environmental effects that, in the opinion of the responsible Minister (now vested in the National Environmental Standards and Regulations Enforcement Agency), 'are likely to result from the project in combination with other projects that have been or will be carried out' (s. 20.4) are included in the review and decision-making process.

While the Act provides for two classes of assessment, screening (for all developments not included in the mandatory list) and mandatory study (for all activities listed in Schedule 1 of the Act), no specific trigger exists for cumulative effects. The requirement for CEA applies to all development projects, private or public, including those proposed by institutions of government at the local, state and federal levels. An approval could only be granted by the federal minister (or his designate) if the activity in question, 
besides being defensible from a project-specific point of view, is deemed environmentally sound from a cumulative effects perspective - at least in theory.

In 2017, the Act was amended to include a requirement to conduct a SEA for policies, plans and programs that are deemed to have significant environmental implications (s. 59). The Federal Ministry of Environment (the responsible authority) also developed a series of guidelines, including a SEA guideline, a generic EIA procedural guideline and other guidelines specific to oil and gas, urban development, renewable energy and chemical plants. While they are often sketchy with no robust framework to operationalize requirements, a recurrent theme in all the guidelines is the need to address cumulative effects in every major sector and at every scale of development. As of date, no SEA has been developed to test the robustness of CEA consideration within this context.

The blanket provision for cumulative effects for all developments represents a move towards best practice in CEA as advocated for in many studies (Hegmann et al., 1999; Olagunju \& Gunn, 2013). Hegmann et al. (1999), for instance, consider CEA as EIA 'done well'. However, translating legal provisions to practice is a huge gap in the Nigerian context. A review of regulatory processes and selected EIA reports shows that neither a strong cumulative effects guideline or framework exists, nor the detailed consideration of cumulative effects implemented in practice. The 1991 Environmental Guidelines and Standards for the Petroleum Industry in Nigeria remains the only document where some form of expectations for CEA is set out for oil and gas development projects, albeit in an anecdotal manner that only captures the impact of multiple stream crossings and the difference between '[s]hort term, cumulative and long term impacts' (s. 5.6.2.iii).

The adoption of the US National Environmental Policy Act's approach to environmental assessment law with its particular attention to cumulative effects may have been the inspiration for similar development in Nigeria (Ogunba, 2004). Thousands of EIA reports are prepared across levels of government and sectors each year, but no indication that sound CEAs are factored in the decision-making process, especially in the absence of a clear guideline that sets out expectations. There is no evidence that case law is playing any role in interpreting EIA requirements and more specifically with CEA in Nigeria. With three independent systems of EIA, the ability to develop a coordinated approach to CEA 
practice becomes complicated. There is little harmonization and a lack of consistent standards across sectors regarding treatment of cumulative effects, which thus suggests that vague requirements via a decree without commensurate policy and technical guidance will not be enough for project proponents to identify, characterize and evaluate potential cumulative effects in any substantive manner that fulfills its intentions.

A first step to improving CEA practice in Nigeria would be to develop a cumulative effects guideline that explicitly stipulates in legislation or through a similar instrument the issues that are to be taken into account. With a legislated SEA, potential exists for an adoption of an "enlightened" CEA approach that is regional-focused and emphasizes an ecological significance relative to sustainability goals and future scenarios (Gunn \& Noble, 2011; Jones, 2016). Similarly, a centralized EIA system where state and local government jurisdictions have no inputs into assessment processes despite being vested with the authority to create local and regional plans (as per Urban and Regional Planning Decree 88,1992 ) would not be sufficient. Rather, a switch to a rigorous CEA regime that is focused on an approach that reconciles scientific assessments, plan development and social policy is required (Parkins, 2011; Duinker et al., 2013; Olagunju \& Gunn, 2016). This integrated approach to CEA is especially important to reconcile and address the complex mix of environmental pollution (including the notorious issue of gas glaring in the Niger Delta with its local, regional and transboundary effects 7), social justice and livelihood sustainability challenges in its oil producing region of Niger Delta (Giwa et al., 2017; Fawole et al., 2019; Matemilola et al., 2019). Some international EIA jurisdictions (for example, the United Kingdom) demonstrate promising ways to overcome such limitations through collaboration between agencies and levels of governments and through engagement with subject matter expertise across sectors (mining, oil and gas, and transportation, for example). As it stands, CEA in Nigeria has the legal basis to succeed but more work is

\footnotetext{
7 Nigeria Niger Delta region contains over 300 active gas flare sites with an estimated 15.1 billion cubic metres $(\mathrm{bcm})$ of natural gas flared, with impacts spreading to the entire West Africa sub-region (see Fawole, 2019). A 2018 Regulation (Flare Gas (Prevention of Waste and Pollution) Regulations, 2018) introduced by the Federal government to minimize the environmental and social impact of natural gas flaring in the region is mute on its cumulative effects.
} 
required to ensure practice lives up to minimum acceptable standard for good practice CEA.

\section{Regulatory features and variations across jurisdictions}

Cumulative effects assessment is part of EIA process in many of the countries examined, and is adapted to each individual jurisdiction's context. The concept has advanced in certain jurisdictions such as Australia and the United Kingdom where policy, legal and research environments, and attention to SEA have shaped practice. However, even in these countries, practice efficiency, political leadership and explicit guidance are still fundamental issues to be addressed.

Regulatory and legislative instruments have played an important role in mainstreaming CEA into project EIA processes, although each country differs in the approach and level of sophistication of the CEA requirements. The development in CEA research, along with recognition of interactive effects of many major projects, has enabled some countries to enact and evolve EIA legislation that requires explicit consideration of CEA. However, often such legislative provisions are not accompanied with policy guidance that defines expectations, offers clear methodology, or sets implementation requirements for CEA. In most of the jurisdictions discussed in this chapter, national governments have been responsible for setting the legal framework. Owing to the historical volume of EIA practice in Canada, for example, operational guidelines specific to CEA have been available for more than two decades, with the most recent revision having been provided in 2012. However, this is not the norm. Guidance for CEA practice seems to be scant among the countries profiled. In the United Kingdom, industry-specific guidelines have been developed, for example, that are specific to infrastructure issued by the Planning Inspectorate. Most often, any CEA guidance that does exist seems to have emerged in a piecemeal fashion, driven by sectoral interest such as concern for cumulative effects related to water management, and so on.

Unlike in Canada where case law has had at least some (but overall quite minimal) influence in the interpretation of cumulative effects (for example, West Moberly First 
Nations v. British Columbia (Chief Inspector of Mines), 2011, BCCA 247 (CanLII))8, in New Zealand and other countries, legal challenges involving CEA are reportedly limited, thus legal understandings of expectations for CEA practice in terms of its scope, rigour and implementation seem to be in an early stage of development.

All eight countries discussed here are facing some form of capacity challenges in implementing CEA in a way that aligns with best practice principles. The shortage of experts is a universal challenge, but the problem is especially acute in countries with weak institutions for EIA. Except in Brazil where some form of legal guidance for addressing cumulative effects has been developed for its oil and gas sector, none of the other developing countries has been able to create a CEA-specific policy document to guide practice, in large part due to absence of technical knowhow and adequate institutional capacity to enforce requirements (for example, Ghana). The lack of reconciliation between competing legislative instruments (for example, Nigeria has three EIA laws with overlapping jurisdictions) further complicates the capacity to develop a coherent, consistent approach to CEA. Mexico's federal law restricts CEA consideration to a retrospective exercise that excludes "the foreseeable future", and instead directs focus to current changes to project environment.

Capacity to effectively implement CEA needs different levels of intervention. In the developed countries, practice in Australia, Canada and the United Kingdom, for example, has been shaped substantially by industry experts, particularly those in the extractive sectors. In part, capacity building has been driven by parliamentary and agency inquiries emphasizing the risks of cumulative effects of the extractive sector on water resources. In Australia and the United Kingdom, external, independent review and evaluation as a complement to proponents' reports may suggest increased rigour and better quality of assessment. However, these interventions are limited by other institutional challenges, including limited data sharing, lack of consistency and transparency on approach and

\footnotetext{
8 The Court of Appeal for the Province of British Columbia (Canada) ruled that project proponents must include the understanding of the nature and extent of historic and cumulative impacts to Aboriginal rights and take a broad, forward-looking approach to cumulative impacts assessment in relation to Aboriginal rights. It is important to note, however, that this ruling is specific to its Aboriginal law context and does not reflect or inform CEA practice as part of the general EIA regime in Canada.
} 
expectations, and a practice approach that typically excludes small-scale projects which usually constitute a majority of assessments. Project splitting as a way of circumventing the need to do a CEA has been cited in the case of Mexico. This practice, however, may be more universal than is thought, especially in jurisdictions where requirements for CEA is limited to major projects (for example, Canada).

Some countries have successfully expanded their legislation to include explicit provisions for SEA (Nigeria, for example) and/or regional EIA (Mexico, for example). These legal developments, as well as voluntary SEAs and REAs in other jurisdictions (Australia, New Zealand and Canada, for example), have the potential of offering meaningful context to CEA practice and are potentially capable of strengthening practice more quickly than the traditional project-based approach. It is important, however, to recognize that SEA approaches in many countries continue to be limited by project proponents' expertise, subjective experience, and business interests. Coordination between environmental and planning institutions is evidently a key requirement for strengthening CEA within a SEA framework to realize long-term, strategic outcomes that transcend individual project development.

\section{Conclusion}

This chapter shows that the concept of CEA is evolving from a strictly project-based approach towards a more strategic and regional context that is explicitly being promoted through EIA legislation in many jurisdictions. Despite this apparent progress, realizing best practice in CEA is a continuous work in progress that requires stronger political commitment, improved technical knowledge, and a systems approach that bridges the legal, scientific and development planning imperatives across geographical scales and levels.

Developed countries are leading in sector-based innovations, industry-led guidance, and peer review and evaluation, though the need for strengthened government leadership and ownership of the CEA process is common to all the national systems described in this chapter. In developing countries, the foundations for CEA to thrive are being laid through legal provisions and explicit recognition of higher-order assessments such as SEA and 
REA, but technical know-how is reportedly limited and improved practice will depend also on innovative strategies that address institutional fragmentation and consistency in implementation. Across all countries, increased data sharing is necessary to capture the effects of many small projects on a cumulative basis, and political leadership is required to advance practice. Central to these challenges are questions such as whether developers should be held accountable to cumulative impacts beyond their projects and, with the exclusion of small projects from CEA in many jurisdictions, how close can we get to understanding the 'full' cumulative impacts of human developments? These questions remain unanswered. Overall, despite being fraught with many challenges, commitment towards improved CEA practice continues to grow, and lessons drawn from the eight countries discussed in this chapter may be helpful in efforts to design and implement reforms that are effective in the long run and contribute to more environmentally responsible decision-making.

\section{Acknowledgement}

Dr. Rebecca Nelson acknowledges the research assistance of Lara Shirley in relation to the Australian component of the chapter and funding from the Australian Research Council ('Regulating Cumulative Environmental Effects: Designing Global Best Practice', Project ID \#DE180101154).

\section{References}

Abaza, H., Bisset, R. and Sadler, B. (2004). Environmental impact assessment and strategic environmental assessment: Towards an integrated approach. United Nations Environment Programme (1st ed.).

ACT Government. (2017). Proponent's guide to environmental impact statements. Canberra: Australian Capital Territory Government. 
Australian Senate Environment and Communications References Committee. (2018). Adequacy of the regulatory framework governing water use by the extractive industry.

Bates, G. M. (2016). Environmental law in Australia (9th ed.). Chatswood, NSW: LexisNexis Butterworths.

Baxter, K. W., Ross, W. A., \& Spaling, H. (2001). Improving the practice of cumulative effects assessment in Canada. Impact Assessment and Project Appraisal, 19(4), 253-262, DOI:10.3152/147154601781766916.

Broderick, M., Durning, B., \& Sanchez, L. (2018). Cumulative effects. In R. Therivel \& G. Wood (Eds.), Methods of environmental and social impact assessment (4th ed., pp. 649677). Abingdon, UK: Routledge.

BSI, (2015). Environmental impact assessment for offshore renewable energy projects guide (PD 6900: 2015). London: The British Standards Institution.

Canadian Environmental Assessment Agency. (2016). Reference guide: Determining whether a project is likely to cause significant adverse environmental effects. Retrieved from https:/www.ceaa-acee.gc.ca/default.asp?lang=En\&n=D213D286-1.

Canter, L. (2012). Guidance on Cumulative Effects Analysis in Environmental Assessments and Environmental Impact Statements. National Oceanic \& Atmospheric Administration National Marine Fisheries Service. US Department of Commerce.

Canter, L., \& Ross, B. (2010), State of practice of cumulative effects assessment and management: The good, the bad and the ugly. Impact Assessment and Project Appraisal, 28(4), 261-268. 
Clark, M., Rouse, H., Lamarche, G., Ellis, J. \& Hickey, C. (2017). Preparation of Environmental Impact Assessments: General guidelines for offshore mining and drilling with particular reference to New Zealand. Wellington, NZ: National Institute of Water \& Atmospheric Research Ltd.

CONAMA, Ministry of the Environment. (1986). Resolution No. 001., Brazil (D.O.U. 17/2/86, section 1, pp. 2548-2549). Brazil.

Creasey, R. \& Ross, W. (2009). The Cheviot Mine project: cumulative effects assessment lessons for professional practice. In K.S. Hannah (Ed.), Environmental impact assessment: Practice and participation, (2nd ed., p. 158-172). Toronto, ON: Oxford University Press.

Department of Planning and Environment (NSW). (2016). Wind energy guideline for state significant wind energy development. Sydney, NSW: New South Wales Government.

Department of Planning and Environment (NSW). (2018). Improving environmental impact assessment. Sydney, NSW: New South Wales Government. Retrieved from https://www.planning.nsw.gov.au/Policy-and-Legislation/Under-review-and-new-Policyand-Legislation/Environmental-Impact-Assessment-Improvement-Project.

Department of Sustainability and Environment (Victoria). (2006). Ministerial guidelines for assessment of environmental effects under the Environment Effects Act 1978 (7th ed.). Melbourne, Vic: State of Victoria.

Department of the Environment (Commonwealth). (2013). Significant impact guidelines 1.3: Coal seam gas and large coal mining developments - impacts on water resources. Commonwealth of Australia. Retrieved from: https:/www.environment.gov.au/system/files/resources/d078caf3-3923-4416-a7430988ac3f1ee1/files/sig-water-resources.pdf 
Department of Petroleum Resources (DPR). (1991). Environmental guidelines and standards for the petroleum industry in Nigeria (EGAS) (2001 revised ed.). Lagos, Nigeria: Department of Petroleum Resources.

Duinker, P., Burbidge, E., Boardley, S., \& Greig, L. (2013). Scientific dimensions of cumulative effects assessment: Toward improvements in guidance for practice. Environmental Reviews, 21(1), 40-52.

Durning, B., \& Broderick, M. (2015). Mini review of current practice in the assessment of cumulative environmental effects of UK offshore renewable energy developments when carried out to aid decision making in a regulatory context. Retrieved from https:/nerc.ukri.org/innovation/activities/energy/offshore/cea-mini/.

Durning, B., \& Broderick, M. (2019). Development of cumulative impact assessment guidelines for offshore wind farms and evaluation of use in project making. Impact Assessment and Project Appraisal, 37(2), 124-138.

Environment Protection Authority (Tasmania). (2019). Guidelines for preparing an environmental impact statement. Hobart, TAS: Environment Protection Authority.

Environmental Protection Authority (Western Australia). (2018). Environmental impact assessment (part IV divisions 1 and 2) procedures manual: Requirements under the Environmental Protection Act 1986. Perth, WA: Government of Western Australia.

Environmental Protection Authority (New Zealand). (2013). Approach to impact assessment. Wellington, NZ.

Environmental Protection Agency of Ghana (EPA), (1999). Environmental Assessment Regulation, 1999, Legislative Instrument 1652 (pp.1-24). Retrieved from: http://extwprlegs1.fao.org/docs/pdf/gha78169.pdf 
Environmental Protection Agency of Ghana (EPA),- (2010). The Environmental Protection Agency Act, 490, December 1994 (pp.1-25). Retrieved from: http://extwprlegs1.fao.org/docs/pdf/gha13234.pdf.

European Commission. (2013). Guidance on integrating climate change and biodiversity into environmental impact assessment. European Union. Retrieved from https://ec.europa.eu/environment/eia/pdf/EIA\%20Guidance.pdf

Fawole, O. G., Cai, X., Abiye, O. E., \& MacKenzie, A. R. (2019). Dispersion of gas flaring emissions in the Niger delta: Impact of prevailing meteorological conditions and flare characteristics. Environmental Pollution, 246, 284-293.

Giwa, S. O., Nwaokocha, C. N., Kuye, S. I., \& Adama, K. O. (2017). Gas flaring attendant impacts of criteria and particulate pollutants: A case of Niger Delta region of Nigeria. Journal of King Saud University-Engineering Sciences, 31, 209-217.

Glasson, J., \& Therivel, R. (2019). Introduction to environmental impact assessment (5th ed.). Abingdon, UK: Routledge.

Gonzalez, J. C. T., de la Torre, M. C. A., \& Milan, P. M. (2014) Present status of the implementation of strategic environmental assessment in Mexico. Journal of Environmental Assessment Policy and Management, 16(2).

Government of Canada. (2018). Assessing cumulative environmental effects under the Canadian Environmental Assessment Act, 2012 (version 2). Retrieved from https://www.canada.ca/en/environmental-assessment-agency/services/policyguidance/assessing-cumulative-environmental-effects-ceaa2012.html. 
Government of Canada. (2015). Designating a project under the Canadian Environmental Assessment Act, 2012. Retrieved from https:/www.canada.ca/en/environmentalassessment-agency/services/policy-guidance/designating-project-under-canadianenvironmental-assessment-act-2012.html.

Government of Ghana. (2010). Strategic environmental assessment of the transport integration plan of Ghana: Environmental report. Southampton, UK: Mott MacDonald. Retrieved from https://europa.eu/capacity4dev/public-environment-climate/documents/seatransport-integration-plan-ghana-2010.

Great Barrier Reef Marine Park Authority. (2014). Great Barrier Reef Region Strategic Assessment: Strategic Assessment Report. Townsville, Qld: Great Barrier Reef Marine Park Authority.

Great Barrier Reef Marine Park Authority. (2018). Reef 2050 plan: Cumulative impact management policy. Townsville, Qld: Great Barrier Reef Marine Park Authority.

Gunn, J., \& Noble, B. (2011). Conceptual and methodological challenges to integrating SEA and cumulative effects assessment. Environmental Impact Assessment Review, 31, $154-160$.

Harriman, J., \& Noble, B. (2008). Characterizing project and strategic approaches to regional cumulative effects assessment in Canada. Journal of Environmental Assessment Policy and Management, 10(1), 25-50.

Hegmann, G., Cocklin, C., Creasey, R., Dupuis, S., Kennedy, A., \& Kingsley, L., Ross, W., Spaling, H., Stalker, D., \& AXYS Environmental Consulting Ltd. (1999). Cumulative effects assessment practitioners guide. Hull, QC: Canadian Environmental Assessment Agency. 
Hunter, S. (2017). Independent review of the water trigger legislation. Commonwealth of Australia. Retrieved from

https://www.environment.gov.au/system/files/resources/905b3199-4586-4f65-9c038182492f0641/files/water-trigger-review-final.pdf.

IEMA. (2011). Special report - The state of environmental impact assessment practice in the UK. Institute of Environmental Management \& Assessment. Retrieved from https://www.iema.net/assets/uploads/Special\%20Reports/iema20special20report20web.pdf.

IESC. (2018). Information guidelines for proponents preparing coal seam gas and large coal mining development proposals. Independent Expert Scientific Committee on Coal Mining and Coal Seam Gas Development.

Jones, C. (2016). Cumulative effects assessment: Theoretical underpinnings and big problems. Environmental Review, 24, 187-204.

Jackson, J. (2016). Predictions in an uncertain world-Assessing effects under the Resource Management Act 1991. New Zealand Law Society Continuing Legal Education Programme. Retrieved from https://www.environmentcourt.govt.nz/assets/Documents/Publications/NZLS-Predictionsin-an-Uncertain-World-FINAL.pdf

Kaveney, T., Kerswell, A., \& Buick, A. (2015). Cumulative Environmental Impact Assessment Industry Guide. Minerals Council of Australia.

Keys, P. W., Galaz, V., Dyer, M., Matthews, N., Folke, C., Nyström, M., \& Cornell, S. E. (2019). Anthropocene risks. Nature Sustainability, 2(8), 667-673.

Liu, J., Bawa, K. S., Seager, T. P., Mao, G., Ding, D., Lee, J. S. H., \& Swim, J. K. (2019). On knowledge generation and use for sustainability. Nature Sustainability, 2(2), 80-82. 
MacLean, J. (2016). Striking at the root problem of Canadian environmental law: Identifying and escaping regulatory capture. Journal of Environmental Law and Practice, $29,111$.

MacLean, J. (2019). Regulatory capture and the role of academics in public policymaking: Lessons from Canada's environmental regulatory review process. UBC Law Review, 52(2), $479-551$.

MacLean, J., Doelle, M., \& Tollefson, C. (2016). Polyjural and polycentric sustainability assessment: A once-in-a-generation law reform opportunity. Journal of Environmental Law and Practice, $30(1), 36$.

Matemilola, S., Adedeji, O. H., Elegbede, I., \& Kies, F. (2019). Mainstreaming climate change into the EIA process in Nigeria: Perspectives from projects in the Niger Delta region. Climate, 7(2), 29.

Michell, A., \& Wright, J. (2019). Cumulative effects assessment: A call to arms. Institute of Environmental Management and Assessment. Retrieved from https://ransform.iema.net/article/cumulative-effects-assessment-call-arms

Ministry for the Environment (New Zealand). (2006). A guide to preparing a basic assessment of environmental effects. Wellington, NZ.

MMO. (2014). A strategic framework for scoping cumulative effects. A report produced for the Marine Management Organisation (MMO Project No: 1055). Retrieved from https://assets.publishing.service.gov.uk/government/uploads/system/uploads/attachment_da ta/file/389876/MMO1055_Report_Final.pdf

National Infrastructure Planning (n.d.). The Planning Inspectorate. Retrieved from https://infrastructure.planninginspectorate.gov.uk/ 
National Offshore Petroleum Safety and Environmental Management Authority (NOPSEMA) (Commonwealth). (2018). Offshore project proposal content requirements (Guidance Note N-04790-GN-1663). National Offshore Petroleum Safety and Environmental Management Authority (Commonwealth).

Natural England. (2014). Development of a generic framework for informing cumulative impact assessments (CIA) related to marine protected areas through evaluation of best practice. Natural England Commissioned Report (NECR147). Retrieved from http://publications.naturalengland.org.uk/publication/6341085840277504

Nelson, R. (2019). Big time: An empirical analysis of regulating the cumulative environmental effects of coal seam gas extraction under Australian federal environmental law. Environmental and Planning Law Journal, 36, 531-551.

Nelson, R. (2019). Water data and the legitimacy deficit: A regulatory review and nationwide survey of challenges considering cumulative environmental effects of coal and coal seam gas developments. Australasian Journal of Water Resources, 23. doi:10.1080/13241583.2019.1600393.

Ogunba, O. (2004). EIA systems in Nigeria: Evolution, current practice and shortcomings. Environmental Impact Assessment Review, 24, 643-660.

Olagunju, A., \& Gunn, J. (2013). What influences valued ecosystem component selection for cumulative effects in impact assessment? Journal of Environmental Assessment Policy and Management, 15(4), 1-22.

Olagunju, A., \& Gunn, J. (2016). Challenges to integrating planning and policy-making with environmental assessment on a regional scale - a multi-institutional perspective. Impact Assessment and Project Appraisal, 34(3), 236-253. 
Olszynski, M., Stacey, J., MacLean, J., Kwasniak, A., \& Gibson, R. B. (2017).

Sustainability in Canada's environmental assessment. Policy Options. Retrieved from https://policyoptions.irpp.org/magazines/september-2017/sustainability-in-canadasenvironmental-assessment-and-regulation/.

Palen, W. J., Sisk, T.D., Ryan, M.E., Árvai, J.L., Jaccard, M., Salomon, A.K., HomerDixon, T., \& Lertzman, K.P. (2014). Energy: Consider the global impacts of oil pipelines. Nature, 510, 465-467.

Palen, W. J., Sisk, T. D., Ryan, M. E., Árvai, J. L., Jaccard, M., Salomon, A. K., ... \& Lertzman, K. P. (2014). Energy: Consider the global impacts of oil pipelines. Nature News, $510(7506), 465$.

Parkins, J. (2011). Deliberative democracy, institution building, and the pragmatics of cumulative effects assessment. Ecology and Society 16(3), 20.

http://dx.doi.org/10.5751/ES04236-160320

Perevochtchikova, M., \& André, P. (2013) Environmental impact assessment in Mexico and Canada: Comparative analysis at national and regional levels of Federal District and Quebec. International Journal of Environmental Protection, 3(8), 1-12.

PINS, (2019). Cumulative effects assessment (Advice Note 17). Retrieved from http://infrastructure.planninginspectorate.gov.uk/legislation-and-advice/advice-notes/

PINS, (2018). Proposed port terminal at former Tilbury Power Station Tilbury2:

Examining authority's report of findings and conclusions and recommendation to the Secretary of State for Transport. Retrieved from https://infrastructure.planninginspectorate.gov.uk/wp- 
content/ipc/uploads/projects/TR030003/TR030003-001128-

Tilbury2\%20Report\%20Final\%20and\%20Appendices.pdf

Porter, M., Franks, D. M., \& Everingham, J.-A. (2013). Cultivating collaboration: Lessons from initiatives to understand and manage cumulative impacts in Australian resource regions. Resources Policy, 38, 657-669.

Quinn, M., Greenaway, G., Duke, D., \& Lee, T. (2004). A collaborative approach to assessing regional cumulative effects in the transboundary Crown of the Continent. Canadian Environmental Assessment Agency's Research and Development Program. Ottawa, ON: Canadian Environmental Assessment Agency.

RUK, (2013). Cumulative impact assessment guidelines: Guiding principles for cumulative impacts assessment in offshore wind farms. Renewable UK. Retrieved from https://nerc.ukri.org/innovation/activities/energy/offshore/cumulative-impact-assessmentguidelines/

Sánchez, L. E. (2006), Avaliação de impacto ambiental: Conceitos e métodos (2 ${ }^{\text {nd }}$ edição). São Paulo, Brazil: Oficina de Textos.

Seitz, E. N., Westbrook, J. C., \& Noble, F. B. (2013). Assessing large spatial scale landscape change effects on water quality and quantity response in the lower Athabasca River basin. Integrated Environmental Assessment Management, 9(3), 392-404.

SEMARNAT (n. d.). MIA-Regional: Official guidance for regional-type environmental impact statement in México. Secretaría de Medio Ambiente y Recursos Naturales, México. Retrieved from https://www.gob.mx/cms/uploads/attachment/file/121011/Guia_MIARegional.pdf 
Sinclair, J., Doelle, M., \& Duinker, P. (2017). Looking up, down, and sideways:

Reconceiving cumulative effects assessment as a mindset. Environmental Impact Assessment Review, 62, 183-194.

Tilbury2, (n. d.). Proposed port terminal at former tilbury power station tilbury2 tr030003 updated cumulative impact assessment - clean tilbury2 document ref: potll/t2/ex/173. Retrieved from https://infrastructure.planninginspectorate.gov.uk/wpcontent/ipc/uploads/projects/TR030003/TR030003-000929Updated\%20Cumulative\%20Effects\%20Assessment $\% 20-\% 20$ Clean.pdf

Valera, C.A. (2012). Integrated environmental assessment of synergistic cumulative impacts of mining projects. Retrieved from http://www.gnmp.com.br/publicacao/147/

Wilson, J., \& Ward, M. (2011). SEA in New Zealand. In B. Sadler, R. Aschemann, J. Dusik, T. Fischer, M. Partidario, \& R. Verheem (eds.) Handbook of Strategic Environmental Assessment (pp. 59-73). Abingdon, UK: Earthscan.

Yaldhurst Quarries Joint Action Group v. Christchurch City Council \& Harewood Gravels Limited. Decision No. [2017] NZEnvC 165. 